Accepted 22.11.2017 for publication by SEXUAL HEALTH

\title{
Chemsex as Edgework: Towards a Sociological Understanding
}

Ford Hickson, BSc BA PhD FHEA

London School of Hygiene \& Tropical Medicine

15-17 Tavistock Place

London WC1H 9SH

United Kingdom

Telephone: 02079272791

ford.hickson@Ishtm.ac.uk

\section{ABSTRACT}

Sexual sessions between men, organised through mobile technologies and combined with stimulants intended to extend and intensify the session, have been reified into the phenomena of 'chemsex'. Understanding chemsex requires multiple levels of analysis and interpretation. This paper considers chemsex through the lens of edgework, a sociological category for voluntary risk taking identified in 1990 by Stephen Lyng. Edgework activities involve a clear and present danger to the self, intense emotions and sensations and an opportunity to exercise specialist skills. Using published research and other cultural products, I demonstrate that chemsex fully exhibits all the defining features of edgework. Chemsex is then positioned as an activity that epitomises the (gay) citizen as consumer in a technocapitalist age of pharmaco-pornographic consumption. 


\section{INTRODUCTION}

For several years now, debates about the health of homosexually active men have revolved around two subjects: oral chemo-prophylaxis for HIV infection (known, including typographically, as 'PrEP') and a particular form of combining sex and illicit drugs, known as 'chemsex'. It is striking that both topics involve chemical products for the management of sex, another indication of the broad social trend toward the bio-medicalisation of sex. ${ }^{1}$

While chemsex has been blamed for a rising number of HIV infections, PrEP is now being credited with a decline. Chemicals, and the products created from them, dominate our lives. We live in a pharmaceutical age. The discovery and synthesis of human hormones in the mid-twentieth century swept away the destinies tied to our anatomies and ushered in a new age of pharmacopossibilities. Which is why we are so excited by PrEP, why PrEP is so exciting. According to Paul Perciado, the objects of political management (bodies, sex, leisure, gender) are, in third-stage capitalism, managed through the tools of 'technocapitalism, global media and biotechnologies'. (p.25). Smartphones and chemicals are among the key tools through which people meet the challenges set down by the availability of chemicals and smartphones. This phenomena is exemplified in chemsex.

Like the term 'bareback', the term 'chemsex' is not a neutral description of behaviour. The terms mean different things to different people, and both carry with them a set of unspoken assumptions about what they signify. Bareback is not simply anal sex without a condom - its equestrian root implies it is also wild, uninhibited, natural and unpredictable. Similarly, chemsex is not simply erotic activity on drugs - it indicates a particular social niche, a set of intentions and expectations, a collection of associated meanings. Crucially, both words signify otherness; barebacking and chemsex are more often used to talk about other people (or our own pasts) than they are to talk about our (current) selves. Despite being used by men who engage in them, both words signify participation in a sub-subculture. (The subtitle of one first-hand account of gay sex 
and drugs is 'Life in the Chemsex Underworld'. ${ }^{2}$ ) This is why the gay community movements in London about talking in response to chemsex are so significant. Events such as Let's Talk About Gay Sex and Drugs (a regular open-mic night in a gay venue for sharing of perceptions and experiences) and the 56 Dean Street Well-Being Programme (an on-going series of educational, artistic and cultural events focussed on LGBT community engagement) provide spaces for bringing chemsex into the community mainstream, simultaneously reifying the phenomena.

Since the beginning of the AIDS epidemic, combining sex with illicit drugs has been identified as a 'high risk practice' for gay men and it remains so. The HIRI Risk Index ${ }^{3}$ (an HIV risk screening tool for use in sexual health clinics) consists of only 7 questions and gives a score from zero to 47 . A score of 10 or over is judged to be indicative of future HIV seroconversion. Two of the seven items concern drug use. The ongoing documentation of the association between combining sex with drugs and a range of harms should no longer surprise us. ${ }^{4}$

How we account for chemsex sets the stage for how we respond to it. To understand chemsex we need multiple lenses and multiple levels of enquiry. Chemsex has a history connected to the criminalisation of homosexuality, the marginalisation of gay communities, and the tolerance of other illegal activities within those communities. The long-view on chemsex includes a history of drug control and the development of new psychotropic substances, as well as a history of pleasure and its importance for people who believe happiness is out of their reach. ${ }^{5}$

Chemsex also has an economics: a micro-economics of the exchange of sex for drugs and drugs for sex that occur on the chemsex scene; a meso-economics of the gay leisure-sex industry that requires on-going partner change in order to operate; and a macro-economics of the international narcotics trade and its interactions with law enforcement.

Chemsex has a psychology, and a psychopathology. Not all MSM are involved or wish to be involved in the chemsex scene, and not all of those who try it are destroyed by it. There are valid questions about why these men and not those men. What are the socio-psychological 
characteristics of the men attracted to this activity? What is the 'vocabulary of motive' in chemsex? What is the best way to help men out of it? This is therefore the realm of toxicity, abuse, health-threat, impairment, inability, trauma and transmission-risk. ${ }^{6}$

Finally, chemsex has a sociology. Accounting for the gay chemsex scene requires an understanding of socially constructed selves in a specific historic and social environment. So there are also valid questions about the recent rise of chemsex. Why here not there, why now not then? What is the broader socio-historical context in which the current phenomenon is situated and what are the sociologically relevant features of chemsex?

This paper is an attempt to bring together a number of chemsex threads in psychology and sociology to better define, appreciate and respond to the phenomena. Chemsex is a new way of talking about the fast-lane gay lifestyle that features in most stories about the start of the AIDS crisis. That the story had such currency in the mid-1980s is no coincidence, given that this was the beginning of a third-stage capitalism characterised by conspicuous consumption, individualism and free market economics. The fast-lane gay lifestyle is, I am venturing, a gay version of extreme sports, the sports which have gained increasing popularity since the 1970s, in which predominantly among young men take large and voluntary risks while, for example, scuba diving, free climbing, and leaping from aeroplanes, buildings and cliffs with parachutes or wingsuits (or in the case of parkour, neither).

What counts as chemsex at the micro level is contentious. Different actors in, and commentators on, the chemsex scene define what is and what is not chemsex in different ways. A number of definitions have been offered but to attempt to mediate between them to find a true definition is to mistake the category for an activity. However, if chemsex is having sex for extended periods of time on drugs, especially stimulant drugs, this requires management if one is going to have the best sex with the least harm. 


\section{IS CHEMSEX A TYPE OF EDGEWORK?}

In 1990 American sociologist Stephen Lyng published a seminal paper on what he called Edgework, in which he outlined a sociological account of voluntary risk-taking. Lyng was concerned with both the motivations of those involved in voluntary risk taking, as well as drawing links between those motivations and the structural, or macro, features of American society at the end of the 1980s. Lyng proposed edgework to be a variety of human experiences that involve three components: an activity that presents a clear threat to well-being or one's sense of an ordered existence; the negotiation of some kind of boundary or edge (between chaos and order, consciousness and unconsciousness, sanity and insanity, life and death); and a defining of "the limits of performance for a particular object or form" (p.858).

Lyng's theory recognised that some people engage in risky activities as an end in themselves, rather than risk as a means to an anticipated reward, the dominant psychological model of risktaking behaviours at the time. People involved in edgework are not taking risks instrumentally in order to gain something. They are choosing to experience negotiating an edge. Nor are they selfharming. The point is to come out of the experience unscathed.

Recent applications of the edgework perspective to explore and account for voluntary risk-taking have included women body building in the USA ${ }^{7}$, men purchasing sex from women in Hong Kong ${ }^{8}$, young people driving while intoxicated in Denmark ${ }^{9}$, probation work in the UK ${ }^{10}$, skydiving in Canada ${ }^{11}$ and internet stock-trading in Sweden ${ }^{12}$. Edgework has also been used to provide a nonpathologising account of condomless anal sex between men (ie. barebacking). ${ }^{13} 14$

There are striking similarities between Lyng's descriptions of the social psychology of extreme sports (and more generically, a range of edgework activities) and the accounts of chemsex given by some gay men. Gay men's account of chemsex are reflected not only in research reports but in the gay media, social networks and community-based education. For example, SLAMMING, a recent booklet for MSM who combine sex and injecting, provides harm-reduction advice 
interspersed with Tom of Finland-style illustrations and quotes from users interviewed during formative evaluation. ${ }^{15}$ Below, as well as published research, I draw on this booklet to demonstrate that (some) chemsex (for some men) qualifies as edgework.

\section{Chemsex edges}

At a very literal level, many men speak of a border, or edge, over which they would not cross. This might be a particular kind of drug (some men draw the line at crystal methamphetamine), a mode of administration (injecting was the one way many men would not put drugs into their body), a frequency of use or a setting. Men combining sex and drugs usually attempt to establish some personal boundaries. ${ }^{16}$ The same notion appears in the SLAMMING leaflet:

“No matter how horny I am, I never share needles or syringes. That's where I draw the line." W.(39)

Men engaging in chemsex are not without their own rules of conduct; they do not usually see themselves as out-of-control. Men's language about the line they will not cross suggests it is an edge, and that they think of chemsex as going up to the edge but not over it. However, the edge they draw is well beyond where health promoters and educators would draw it.

\section{Dangerous Activities}

Along with all other edgework activities, chemsex involves "a clearly observable threat to one's physical or mental well-being, or one's sense of an ordered existence" (Lyng, p.857). Most men involved in chemsex have experienced or witnessed harms including psychosis, infections, physical trauma, death. ${ }^{17}$

Along with other edgeworkers, chemsexers often acknowledge the potential harms but exclude themselves from being at risk. This is more than routine optimistic bias. Those at risk are the men 
who do not know what they were doing. Berating other men as naïve or inexperienced allows the development of a sense of control over an essentially random and chaotic situation. However, the number of unknown variables involved in chemsex mean that the sense of mastery men develop is largely illusory, much like the illusion of stock-picking skills among investment managers. ${ }^{18}$ The men who come out of chemsex unscathed are simply those who have not yet fallen prey to its randomly allocated harms.

\section{Displaying Specialised Skills}

Lyng identifies all kinds of edgework as involving "the use of specific individual capacities" (p.858). Edgework provides a space for people to exercise specialist skills. Chemsex includes the skills associated with both taking drugs and the skills associated with having sex. Sex skills are role specific, so it is worth distinguishing top-skills and bottom-skills. They include knowing how to touch and manipulate a body, being good at fellating, being able to receive as much anal sex as a partner can give, keeping endlessly hard. Being able to do these things for very extended periods of time is required to explore the limits of sexual performance. Chemsex is a particularly athletic from of edgework.

Drug taking also provides space for the display and employment of knowledge, including how to obtain them, which drugs not to mix (eg. alcohol and G; Viagra and poppers), planning, arranging, following behavioural rituals, measurement and dosing (especially of $\mathrm{G}$ ), timing, re-stocking. All are opportunities for the deployment of knowledge and the application of skills. Like other drug scenes, the chemsex scene abounds in folk pharmacology and lay experts. ${ }^{19}$ Drug skills also include injecting. SLAMMING suggests 'If you like slamming it makes a lot of sense to learn how to do it well.' Men reveal the importance of skills through criticism of other men's lack of them:

“Hardly anybody knows how to slam correctly. People learn from each other. I often think, I really hope this ends well." (SLAMMING, p.35) 
Another set of chemsex skills include knowing how to manage other users who have overdosed or are anxious, paranoid or psychotic. Preparing for and knowing how to best come down from a chemsex session is a final area of skill deployment. The chemsex scene can be an arena of sharing and caring in which a harm reduction culture emerges 'from below' (ie. from users rather than experts). ${ }^{20}$

The most important chemsex skill, the one shared with all other types of edgework, is "the ability to maintain control over a situation that verges on complete chaos, a situation most people would regard as entirely unacceptable" (Lyng, p.859). Engaging in chemsex successfully requires a special kind of mental toughness if one is not to be destroyed by it. Men who are destroyed by chemsex, according to this perspective, simply did not have 'the right stuff'. This belief in special skills results in an elitist orientation. That the activity is only for a special kind of person.

\section{Intense emotions and sensations}

Lyng claims that all types of edgework produce a sense of self-realisation, self-actualisation, or self-determination - that edgework calls forth the ego in a particularly dramatic way. Fear is a common emotion in the early stages of an edgework experience. However, this sense of fear gives way to feelings of exhilaration and omnipotence.

Descriptions of edgework often include the experience of self-actualisation or liberation. Chemsex is defined by intense emotions and sensations. Weatherburn et al. quote one man: "It was the best sex I ever had. Really the best orgasm I'd had. I used to say it was like the heavens opened and it was like the light came down when I had an orgasm. Because it was that intense on drugs, it really was." ${ }^{21}$

Similarly, the SLAMMING leaflet identifies this as a key feature in the allure of chemsex: 
"The effect of slamming is very intense, and for me it is equivalent to freedom...I feel liberated from past sexual issues." M.(42)

The intense emotions experienced in chemsex, including bonding, love and emotional connection, is a major incentive to participate..$^{22}$

Lyng claimed that most fundamentally, high-risk behaviours involve "the problem of negotiating the boundary between chaos and order" (p.855). A common experience in chemsex is the losing of one's own boundaries. Men talk about bodily merging with their sexual partner, of the boundary between themselves and the other dissolving, or of being one with the universe. Edgework typically involves altered perceptions and consciousness, particularly in the perception of time. People involved in edgework find it difficult to gauge the passage of time. Also typical is a highly focussed perceptual field. In chemsex, drugs psychopharmologically create the sensations associated with non-drug types of edgework. Sex on stimulants really is like skydiving in any number of ways.

Defining the limits of sexual performance

Lyng suggests edgeworkers typically explore both the limits of themselves and of a technological form (p.858). Chemsexers attempt to explore their personal limits to sexual performance. Drugs make this possible. Chemsex displays this quality both in the duration and rate of sexual acts and in the number of men engaged with. Weatherburn et al. quote one man:

"So for me and this guy, we would smoke it [crystal] together and literally just fuck him for 12 hours, non-stop and it was brilliant. It was just-you feel super human, he can take it and take it. You give it and give it."

The challenge to gay men is laid down by contemporary gay pornography, products of the gay leisure-sex industry and the techno-capitalist consumer society. 'Gang-bang' and 'marathon' porn 
are established genres in the gay world as well as the straight world. There are also the performance limits set down by the apps - the apparently endless gallery of sexual partners. To meet the challenge of Grindr all men must become porn stars.

Professionally published accounts of chemsex come from a particular point of concern, which is typically focussed on the harms chemsex causes and the care that can be applied to men suffering. Contrasting with the harm and care focussed account are other cultural accounts of chemsex. One forceful alternative account comes from pornography company Treasure Island Media, or TIM, an American company that also operates in Britain. TIM has been at the forefront of depicting and promulgating an excessive mode of sexual interaction, defining the limits of sexual performance. The 2004 film 'Dawson's 20 Load Weekend' is reputedly one of the most frequently watched gay porn film and depicts a man's quest to anally receive the ejaculate of 20 men over a single weekend. But "So many men, so little time" has been an integral part of modern gay identity for some decades. It was the name of a 1983 single by Miquel Brown, one of the biggest hi-energy disco hits of the early 1980s (the video consisted of semi-naked muscle-men weightlifting in a disco). Grindr an dother hook-up apps present gay men with a challenge by giving access to so many more men. Drugs enable men to meet that challenge but the challenge does not dissolve, it shifts into another challenge. Ahmed quotes one man observing this process:

"I think it's the danger with sex at sex parties and all the fun things, you always want to put the bar up higher to get a higher satisfaction as well. And sometimes, yeah, sometimes it goes too far."

Going too far has a long history in gay pleasure. As Oscar Wilde has Lord Illingworth claim in $A$ Woman of No Importance, moderation is fatal and "nothing succeeds like excess" (Act III). In sum then, the published account of chemsex and the cultural artefacts associated with it (pornography, harm reduction texts) suggested chemsex contains all the features of edgework delineated by Lyng: conspicuously dangerous activities that provide an arena for the display of 
highly specialised skills and which evoke intense sensations and emotions as the limits of performance are explored.

\section{LOCATING CHEMSEX AS EDGEWORK}

Since the 1980s the driving force for research into drug use and sex between men has been their relationship to HIV and other sexually transmitted infections. Increasingly sophisticated research designs have narrowed the field of drug culprits. That men who take drugs (of various classes) are more likely to engage in a range of sexual behaviours (most of which can be construed as risks) than men who do not take drugs continues to be demonstrated in cross-sectional surveys. That sexual sessions featuring binge drinking or crystal methamphetamine are more likely to include intercourse and are less likely to include condoms than sexual sessions that do not feature drugs has also been shown. ${ }^{23}$ Thirdly, panel data from the same men at different points in time show that the same men having sex on crystal methamphetamine are more likely to have condomless anal sex than they are having sex on the drugs or without drugs. ${ }^{24}$ Much time and energy has gone into (continues to go into) debating the associations between drugs, sex and risk. Investigations of the role of context in the interaction between drugs, sex and risk have led to an understanding of life as an assemblage of embodied practices in space..$^{25}$ Only lately has subjective experience entered this field, usually under the name of 'affect'.

The subjective experiences of chemsex most commonly articulated in research and culture are those of extremes. These include the extremes of pleasure, as well as the extremes of misery. It is worth noting that the chemsex scene can also be banal and include large doses of boredom, distraction and frustration. But the experiences men are seeking are (for them) positive ones. Although curiosity and a desire to belong may initially motivate men to engage in chemsex, it is the memories of positive experiences that brings them back to it, even when those positive experiences become harder and harder to recreate. 
Lyng's initial framework for edgework included the notion that the modern workplace denies opportunity to flex creativity, develop mastery and to grow personally. Employment conditions, of young men in late 19080s USA in particular, were a central pillar of Lyng's accounting for their participation in edgework. Engagement in chemsex among gay men appears not to be strongly related to education or employment. While there are differences in the proportions of men engaging across these variables, the activity is notable across all groups. However, the circumstances of engagement often differ and harms arising (and the extent of men's resources to respond to them) vary. These harms and resources are distributed according to age, nationality, ethnicity, etc., but are not wholly determinative of them. So education and employment have a definite place in description and discussion of chemsex, but employment would not appear to be the major source of alienation. What seems much more plausible among these men is heterosexist alienation (the alienation experienced by homosexuals in a heterosexual world). ${ }^{26} 27$ There is also the question of why, if chemsex is a form of edgework, that the edgework of gay men is chemsex. Of all the forms of edgework that gay men could engage in, why has chemsex been so commonly invested in? It may be the case that chemsex is the edgework of gay men because gay men have been excluded from other kinds of edgework. Sports ideology has been positively associated with anti-homosexual attitudes. ${ }^{28}$ When homosexuality is understood as weakness, the strength-worshipping extreme sports networks are not welcoming to gay men. It may also be the case that chemsex is simply the most accessible form of edgework available to gay men, a form not easily available to femiphile men given edgework is particularly attractive to males/men rather than females/women. If chemsex were as easily available to femiphile men, would it be as common as it is among androphile men (which nonetheless at a population level, and despite the attention given it, is relatively small $\left.{ }^{29}\right)$ ?

The sex/gender aspects of chemsex warrant more attention. What kind of masculinity does chemsex perform $?^{30}$ A subordinate (or counter) masculinity consisting of emotional and physical 
intimacy which is in opposition to the hegemonic masculinity of interpersonal distance? Or a complicit masculinity (in tops) and a complicit femininity (in bottoms) which valorise the hegemonic masculinity and femininity from which both are excluded by virtue of being queer? Since masculinity is contingent and chemsex is diverse, it is feasible that both (and others) are operating. It is also possible that chemsex is an edgework of abjection, in which an inferior and stigmatised social position (that of the 'passive' male homosexual in particular) is transvalued into pride and resistance. ${ }^{31}$ David Halperin described the gay uses of abjection as an "experiment with the limits of both destruction and survival, social isolation and social solidarity, domination and transcendence" (p.86), strongly echoing Lyng's description of edgework. The sexual politics of chemsex have yet to be fully explored.

Culturally, chemsex (like much contemporary substance use) can be understood as both resistance and conformity. ${ }^{32}$ It can be understood as a form of resistance to the normalisation of homosexuality. In times of gay marriage, employment protection and mundane media representation of gay people, transgression calls for something other than 'straight' gay sex. ${ }^{33}$ The way we talk about chemsex, as something other people do (or something we did in the past), illustrates its underground nature. Understanding chemsex as resistance to bio-medical power places it firmly within the tradition of the gay resistance habitus, the automatic adoption of contrary positions by a community defined by its otherness. ${ }^{34}$

However, chemsex can also be understood as contemporary conformity because it epitomises instant-access shopping culture. The gay sauna is a "space for consumption"35 and smart-phone apps provide home-delivery. Chemsex is a logical activity in a technocapitalist age of pharmacopornographic consumption. ${ }^{36}$ The excess of consumption in chemsex, of drugs, of bodies, is a requisite performance when the mode of production takes second place to the mode of consumption. Market values have infiltrated every aspect of our lives and all our social transactions ${ }^{37}$ In the process we ourselves have become both consumer and commodity. 
Creating our identities through chemicals and pursuing pastimes through consumption is what we do in late-stage capitalism. ${ }^{38}$

\section{CONCLUSION}

Not all men combining gay sex with drugs are engaging in chemsex and not all men engaged in chemsex engaged in edgework. A phenomena as complex and multifaceted as chemsex requires multiple lenses to grasp it. However, the edgework perspective provides one such lens for considering what is going on for some men. It also invites unexamined questions about the relationship of the rise of chemsex to the broader features of both contemporary gay lives and the societies in which they are lived.

In seeking a richer account of and for chemsex I do not seek to excuse or justify it. I am certainly not promoting it. Chemsex is a high-risk activity through which many men's lives fall apart. However, I do believe that a better understanding of what is going on in chemsex, and why, can help men take greater control of their lives. Understandings which posit men engaged in chemsex as weak, stupid, self-hating or subject to irresistible forces do not help men take that control. Characterisations of chemsex as simply 'fun' do not pay attention to what men are seeking or what they get out of it. Quality of life is at the heart of the chemsex debate.

\section{Conflicts of Interest}

The author declares no conflicts of interest.

\section{Acknowledgements}

The author thanks the two anonymous reviewers for their numerous suggestions improving this paper. 


\section{REFERENCES}

${ }^{1}$ Giami A, Perrey C. Transformations in the medicalization of sex: HIV prevention between discipline and biopolitics. Journal of Sex Research. 2012;49(4):353-61. doi: 10.1080/00224499.2012.665510.

${ }^{2}$ Wharton J (2017) Something for the Weekend: Life in the Chemsex Underworld. London: Biteback Publishing.

${ }^{3}$ Smith DK, Pals SL, Herbst JH, Shinde S, Carey JW. Development of a clinical screening index predictive of incident HIV infection among men who have sex with men in the United States. Journal of Acquired Immune Deficiency Syndrome. 2012, 60(4):421-7. doi: 10.1097/QAl.0b013e318256b2f6.

${ }^{4}$ Hegazi A, Lee MJ, Whittaker W, Green S, Simms R, Cutts R, Nagington M, Nathan B, Pakianathan MR. Chemsex and the city: sexualised substance use in gay bisexual and other men who have sex with men attending sexual health clinics. International Journal of STD \& AIDS, 2017, 28(4):362-366. Doi:

10.1177/0956462416651229

5 John Gray, Straw Dogs, London: Granta Books, p.142.

${ }^{6}$ Giorgetti R, Tagliabracci A, Schifano F, Zaami S, Marinelli E, Busardò FP. When "chems" meet sex: a rising phenomenon called "chemSex". Current Neuropharmacology, 2016, 15(5):762-770.

7 Worthen MGF and Baker SA. Pushing up on the glass ceiling of female muscularity: women's bodybuilding as edgework. Deviant Behavior, 2016, 37(5), 471-495.

8 Kong TSK. Buying sex as edgework: Hong Kong male clients in commercial sex. British Journal of Criminology, 2016, 56(1), 105-122.

9 Fynbo L. Risk, control and self-identity: Young drunk drivers' experiences with driving under the influence of alcohol and drugs. Nordic Studies on Alcohol and Drugs, 2014, 31(3), 229-243.

10 Worrall A and Mawby RC. Probation worker responses to turbulent conditions: Constructing identity in a tainted occupation. Australian and New Zealand Journal of Criminology, 2013, 46(1), 101-118.

11 Laurendeau J. "He didn't go in doing a skydive": Sustaining the illusion of control in an edgework activity. Sociological Perspectives, 2016, 49(4), 583-605

12 Zwick D. Where the action is: Internet stock trading as edgework. Journal of Computer-Mediated Communication, 2005, 11(1), Article number UNSP 2.

${ }^{13}$ Holmes D, O'Bryne P, Gastaldo D. Raw sex as limit experience: a Foucaulian analysis of unsafe anal sex between men. Social Theory and Health, 2006, 4:319-333.

${ }^{14}$ Tomso G. Viral sex and the politics of life. In Hall DE and Jagose A, The Routledge Queer Studies Reader, 2012, Abingdon; Routledge, pp.180-193.

15 Preston A and Jones R. Slamming, 2017, London; Exchange Supplies. Adapted from Knoops L and Bakker I, Slamming Dos and Don'ts. 2016, Amsterdam; Mainline Foundation.

${ }^{16}$ Ahmed AK, Weatherburn P, Reid D, Hickson F, Torres-Rueda S, Steinberg P, Bourne A. Social norms related to combining drugs and sex ("chemsex") among gay men in South London. International Journal of Drug Policy, 2016, 38;29-35.

${ }^{17}$ Bourne A, Reid D, Hickson F, Torres-Rueda S, Steinberg P, Weatherburn P. "Chemsex" and harm reduction need among gay men in South London. International Journal of Drug Policy, 2015, 26(12), 11711176. DOI:10.1016/j.drugpo.2015.07.013.

${ }^{18}$ Kahneman D. Thinking Fast and Slow. London: Penguin, 2011, chapter 19.

${ }^{19}$ Southgate S, Hopwood M. The role of folk pharmacology and lay experts in harm reduction: Sydney gay drug using networks. International Journal of Drug Policy, 2001, 12(4):321 - 335.

${ }^{20}$ Van Schipstal I, Mishra S, Berning M, Murray H. Harm reduction from below: on sharing and caring in drug use. Contemporary Drug Problems, 2016, 43(3):199-215.

${ }^{21}$ Weatherburn P, Hickson F, Reid D, Torres-Rueda S, Bourne A. Motivations and values associated with combining sex and illicit drugs ('chemsex') among gay men in South London: findings from a qualitative study. Sexually Transmitted Infections, 2017, 93:203-206. doi:10.1136/sextrans-2016-052695.

${ }^{22}$ Amaro R. Taking Chances for Love? Reflections on Love, Risk, and Harm Reduction in a Gay Slamming Subculture, Contemporary Drug Problems, 2016, 43(3):216-227.

${ }^{23}$ Vosburgh HW, Mansergh G, Sullivan PS, Purcell DW. A review of the literature on event-level substance use and sexual risk behaviour among men who have sex with men. AIDS and Behaviour 2012, 16:1394-410. doi: 10.1007/s10461-011-0131-8. 
${ }^{24}$ Melendez-Torres GJ, Hickson F, Reid D, Weatherburn P, Bonell C. Findings from within-subjects comparisons of drug use and sexual risk behaviour in men who have sex with men in England. International Journal of STD and AIDS. 2017, 28(3):250-258. doi: 10.1177/0956462416642125.

${ }_{25}$ Melendez-Torres GJ and Bonell C. Littoral spaces of performance: Findings from a systematic review and re-analysis of qualitative studies on men who have sex with men, substance use and social venues.

Sexuality Research \& Social Policy, pub online 22 July 2016. doi: 10.1007/s13178-016-0247-8

${ }^{26}$ Downs A. The Velvet Rage Overcoming the Pain of Growing Up Gay in a Straight Man's World. 2005, Cambridge, MA: Perseus Books.

${ }^{27}$ Todd M. Straight Jacket: How to be Gay and Happy. 2016, London: Bantham Press.

${ }^{28}$ Harry J. Sports ideology, attitudes towards women and antihomosexual attitudes. In Andrew Yiannakis and Merrill J. Melnick (eds.) Contemporary Issues in Sociology of Sport. 2001, Leeds; Human Kinetics. ${ }^{29}$ Bourne A, Reid D, Hickson F, Torres Rueda S, Weatherburn P. The Chemsex Study: Drug Use in Sexual Settings among Gay \& Bisexual Men in Lambeth, Southwark \& Lewisham. 2014, London: Sigma Research. www.sigmaresearch.org.uk/chemsex

${ }^{30}$ Connell RW. Masculinities, 1995 (2nd ed. 2005), Cambridge; Polity Press.

${ }^{31}$ Halperin DM, What Do Gay Men Want? An Essay on Sex, Risk and Subjectivity, 2007, University of Michigan Press.

32 Reith G. On the edge: drugs and the consumption of risk in late modernity. In Stephen Lyng (ed.) Edgework. 2005, New York: Routledge, pp.227-245.

${ }^{33}$ Florêncio J. Chemsex: why is gay sex causing straight panic? The Conversation, 12 April 2016. https://theconversation.com/chemsex-why-is-gay-sex-causing-straight-panic-56541

${ }^{34}$ Crossley M, Making sense of barebacking: gay men's narratives, unsafe sex and the 'resistance habitus', British Journal of Social Psychology, 2004, 43(2):225-44.

35 Percy Fernández Dávila, "ChemSex in the sauna": an ethnographic study on the use of drugs in a gay sex venue in Barcelona. Paper presented at The European ChemSex Forum, London, April 2016.

${ }^{36}$ Preciado PB. Testo Junkie: Sex, Drugs, and Biopolitics in the Pharmacopornographic Era. Translated by Bruce Benderson. 2008/2013, New York; Feminist Press.

37 Sandel M. What Money Can't Buy. 2012, New York; Farrar, Straus and Giroux.

${ }^{38}$ Gaissad, L, Expending ourselves at "La Démence ?": gay party circuit from consumption to consummation. Ethnologie française, 2013, 43(3):409-16. 